AperTO - Archivio Istituzionale Open Access dell'Università di Torino

\title{
Categorical rhythms in a singing primate
}

\section{This is a pre print version of the following article:}

Original Citation:

\section{Availability:}

This version is available http://hdl.handle.net/2318/1817536

since 2022-12-21T16:33:14Z

Published version:

DOI:10.1016/j.cub.2021.09.032

Terms of use:

Open Access

Anyone can freely access the full text of works made available as "Open Access". Works made available under a Creative Commons license can be used according to the terms and conditions of said license. Use of all other works requires consent of the right holder (author or publisher) if not exempted from copyright protection by the applicable law. 


\section{Categorical rhythms in a singing primate}

Chiara De Gregorio ${ }^{1}$, Daria Valente ${ }^{1,2}$, Teresa Raimondi ${ }^{1}$, Valeria Torti ${ }^{1}$, Longondraza Miaretsoa ${ }^{1,3}$, Olivier Friard ${ }^{1}$, Cristina Giacoma ${ }^{1 \#}$, Andrea Ravignani ${ }^{4 \# *}$, Marco Gamba ${ }^{1 \#}$

${ }^{1}$ Department of Life Sciences and Systems Biology, University of Turin, Turin, Italy

${ }^{2}$ Equipe de Neuro-Ethologie Sensorielle (ENES), Centre de Recherche en Neurosciences de Lyon (CRNL), CNRS, INSERM, University of Lyon/Saint-Étienne, Saint-Étienne, France

${ }^{3}$ Groupe d'Etude et de Recherche sur les Primates de Madagascar (GERP), Antananarivo, Madagascar.

${ }^{4}$ Comparative Bioacoustics Group, Max Planck Institute for Psycholinguistics, Nijmegen, The Netherlands

\# Co-senior authors.

* Correspondence: Andrea Ravignani, Comparative Bioacoustics Group, Max Planck Institute for Psycholinguistics, Wundtlaan 1, 6525 XD Nijmegen, The Netherlands; andrea.ravignani@mpi.nl

Article type: Correspondence for Magazine section Word count: 989 words (max 1,000 allowed)

Who's got rhythm, and why? One approach to the biology and evolution of musical rhythm consists in finding statistical universals [1]. These are rhythmic features that appear above chance across human musical cultures. One such universal is the production of categorical rhythms, which occurs when note onsets are separated by diserete temporal intervals belonging to few classes [1-3]. Because of categorical rhythms, any song sung (reasonably) faster or slower is still recognizable. Another universal consists in the presence of binary subdivisions, such as those found in the notes of a march $[1,3]$. A parallel approach to the biology of music focuses on finding similarities and differences across species, so to build evolutionary phylogenies of musical traits [4]. Here we combine these two approaches. We show that complex rhythm categories are not, among mammals, unique to humans [5]; we find that a lemur species displays, in its songs, the isochronous and binary rhythm categories seen in human music.

Beyond melodic features (Figure 1A), individual animal vocalizations have onsets (blue lines in Figure 1C). Two onsets delimit an inter-onset interval $\left(t_{k}\right)$, i.e. the time between the onset of a note and the next one $[3,6]$. Ratios between these intervals are calculated by dividing an interval by itself plus its adjacent one [5]. Patterns in these ratios may emerge. For instance, two identical intervals generate a 1:1 ratio, and an interval followed by another twice its duration generates a 1:2 ratio. This approach successfully highlighted rhythmic similarities between birdsong and human music [5]. In particular, for the first time in a non-human species, songs of thrush nightingales and zebra finches showed a significant isochronous rhythmic category and a potential bias towards 1:2 categories [5]. This work advanced the hypothesis that rhythmic categories and isochrony should appear in species showing coordinated group singing [5]. Here we test this hypothesis.

We focused on one of the few singing primates, the lemur Indri indri, sampling approximately $1 \%$ of all living individuals from this critically endangered species. All members of a family group sing in temporally-coordinated duets and choruses [7-8]. Over 12 years, we recorded songs from 20 indri groups living in their natural habitat, the rainforest of Madagascar (Figure 1B and Supplement for details). We extracted temporal features of indris' songs, analyzing inter-onset intervals (Figure 1E) and their ratios (Figure 1D). 
First, we find that note onsets are separated by discrete temporal intervals, and ratios of these intervals form three clusters (green density function in Figure 1D). In other words, the intervals between notes bear similarities to the discrete note durations found in human music [2,5], as opposed to being sampled with the same probability among all possible values (yellow line in Figure 1D). Notice that finding these clusters does, in principle, neither imply that they match specific values nor that these values are integer ratios [3].

Second, we find that ratios match two rhythmic categories: isochrony, similar to the pace of a metronome, and 1:2, a fundamentally small integer ratio. We ask whether ratios produced by each individual fall more frequently in the vicinity of a small integer ratio (called on-integer in Figure 1D) or away from it (off-integer) [5]. By pairing the number of on-integer to off-integer ratios produced by each indri, we find that the empirical rhythmic ratios from songs fall statistically more often on small integer ratios than off integer ratios (Figure 1F). In particular, and similarly to songbirds [5], indri songs have a strong, above chance, isochronous component with some tempo flexibility; indris sing at a slightly decreasing isochronous tempo, similar to musical 'ritardando' [5]. Unlike songbirds [5], indris' empirical ratios statistically match the theoretical 1:2 category (but not the 2:1 category, Figure 1F). This provides direct evidence for one musical universal, categorical rhythms, and suggestive evidence for another one, binary subdivisions [1,3]. The production and perception of metrical temporal hierarchies are, to date, aspects of human musicality yet to be found in any nonhuman species [4]. The binary subdivisions we witness are not direct evidence of meter, though they may result from two nested periodic processes (bottom of Figure 1C).

Third, our data show that, while inter onset intervals differ between males and females (Figure 1E), rhythmic categories are preserved across sexes (see Supplement). This may be relevant to selective hypotheses for music, hypothesizing a role of sexual selection, social bonding, etc. on rhythm origins. Productive inference on how rhythm evolved requires multi-component thinking $[4,6,9]$ : rhythm as a whole is a mystery but some of its defining features may be present in other species, as we show here. Male and female indris may produce different singing tempi and interval durations, but rhythmic categories are the same between sexes. This suggests that sexual selection should not affect the evolution of rhythmic categories in indris (while it may play a role in single interval timing) [4].

Why should another mammal, apart from humans, produce categorical rhythms? As the last common ancestor between humans and indris lived 77.5 MYA, this ability may have convergently evolved among singing species, such as songbirds, indris, and humans [10]. As in songbirds, isochrony and rhythmic categories in indris may facilitate song coordination, processing, and potentially learning [4-7]. Alternatively, one hypothesis links isochrony and categorical rhythms to cultural transmission $[3,5]$. If this holds, and unaware of whether indris show song learning or transmission, our results highlight either an alternative path to isochrony, or the promise of finding cultural transmission in indri.

To conclude, other mammals can spontaneously produce categorical, flexible, and music-like rhythms. Rhythmic universals in other species may be more common than previously surmised. Apart from songbirds, singing mammals are promising species to look for musical universals, offering the advantage of phylogenetic proximity to humans [5]. We encourage more comparative work on indri and other endangered species to gain more data before it is too late to witness their breath-taking singing displays. 

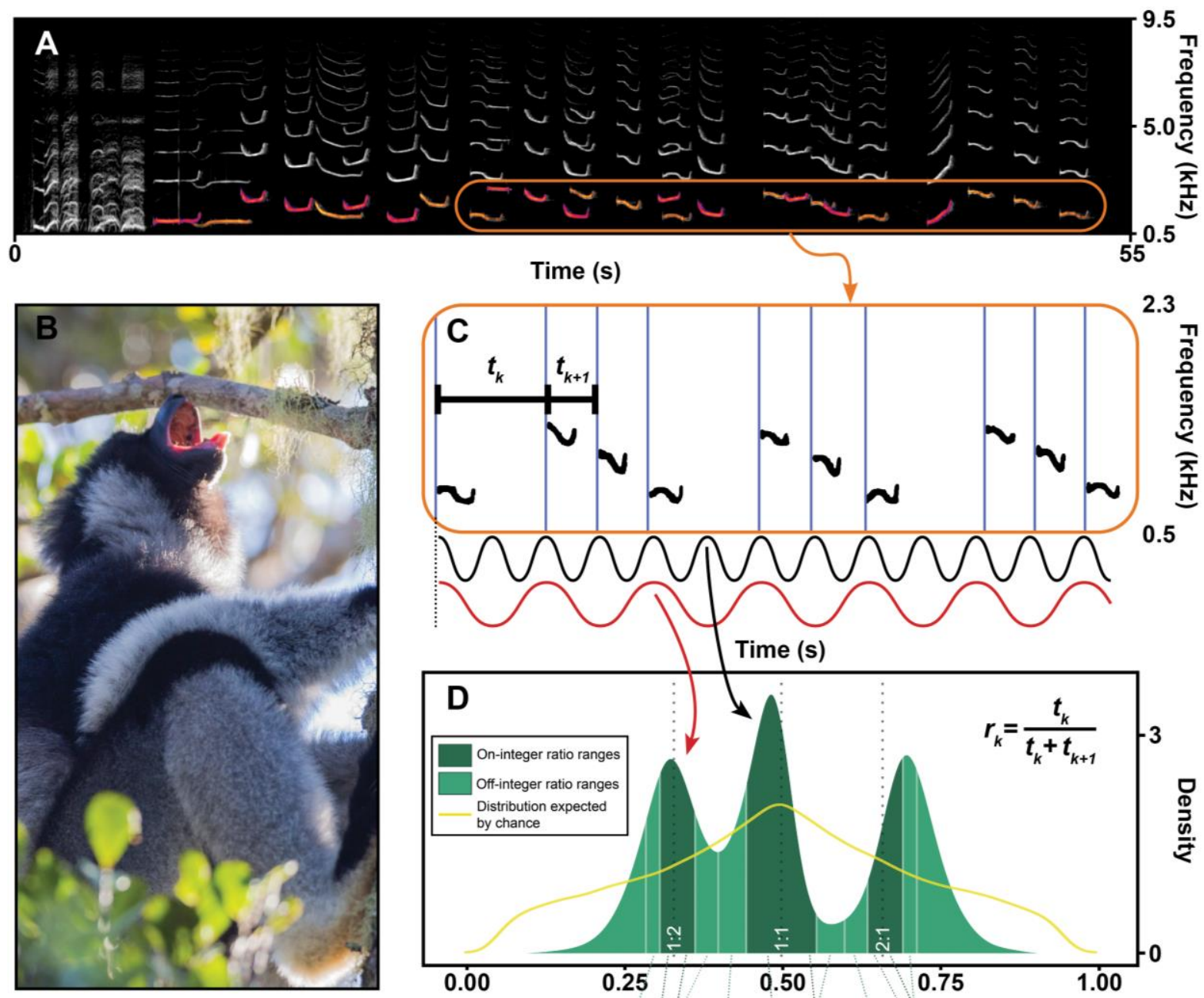
$5_{0.5}^{9.5}$
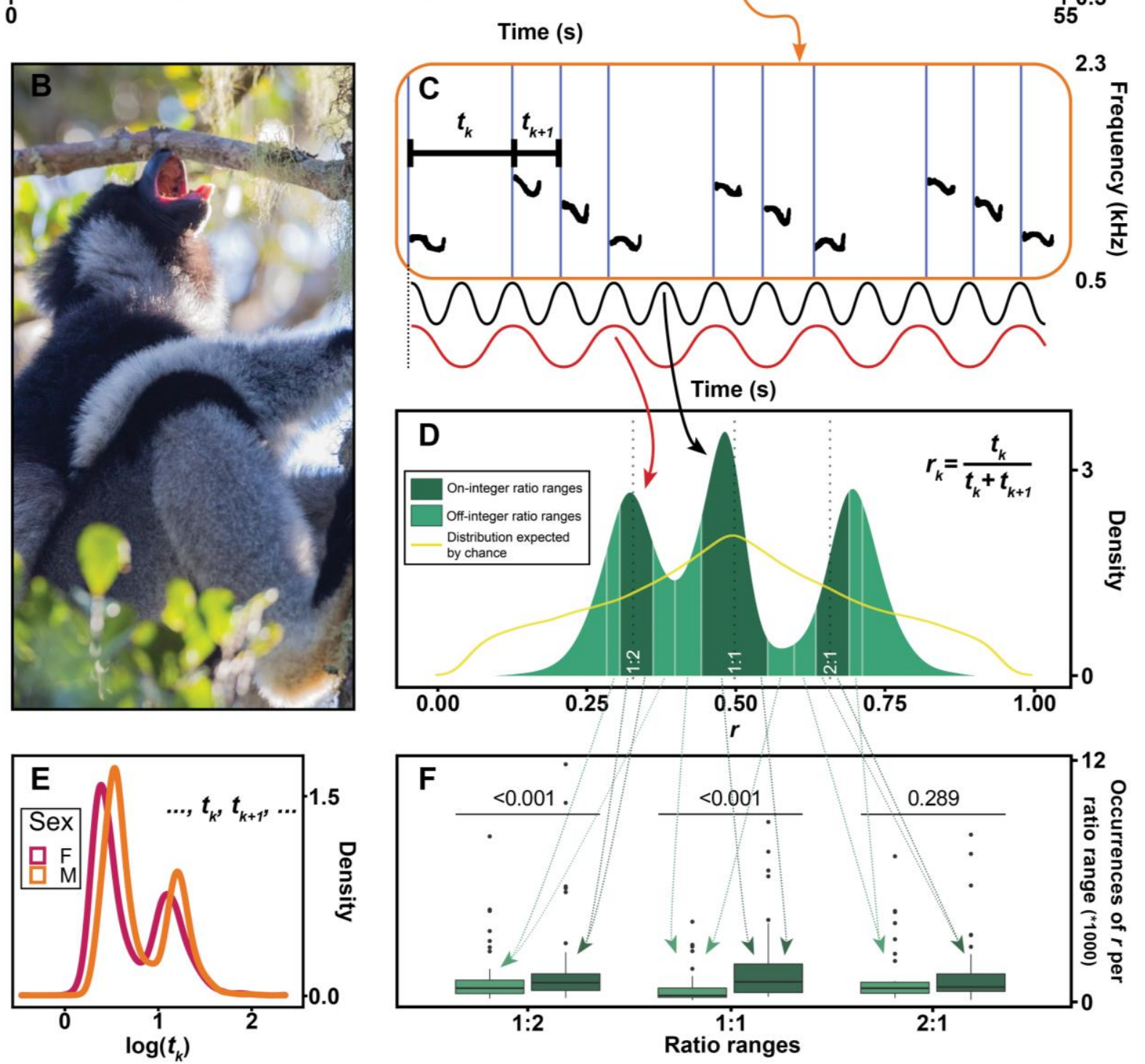

Figure 1. Indris' songs: Extracting individual rhythms from group choruses.

100 (A) Spectrogram of the indris' song, highlighting the fundamental frequencies of male (orange) and 101 female (pink) notes (iZotope RX). The orange inset highlights the male song portion detailed in C.

102 (B) Adult male indri singing in the Maromizaha New Protected Area, Madagascar (Credit: Filippo 103 Carugati).

104 (C) Schematic representation of onsets (solid blue lines) in a male indri song. Pairs of onsets define 105 inter-onset intervals $t_{k}$, marked with solid black lines. Sine waves (bottom) exemplify which 106 purported oscillatory processes might generate the rhythmic categories found in the data: 1:1 ratio in 107 black, 1:2 ratio in red.

108 (D) Probability density function of rhythm ratios $\left(\mathrm{r}_{\mathrm{k}}\right)$, which we calculated across 39 adult indris and 109636 individual contributions to songs. On-integer (dark green) and off-integer (light green) ratio 110 ranges are highlighted. A markedly different null distribution (yellow line, simulated from actual 111 indri data) would be expected in the absence of rhythmic categories. 
112 (E) Probability density function of inter-onset intervals $\left(t_{k}\right)$, depicting dimorphism between sexes 113 (i.e., a statistically significant sex difference, see Supplement).

114 (F) Boxplots of adjusted $\mathrm{r}$ occurrence for on-integer (dark green) and off-integer (light green) ratio 115 ranges. The ratio counts for individual indris constitute the data points for the analysis, and counts 116 are normalized by bin size (see Supplement). Indris significantly produce more on-integer than off117 integer ratios for the 1:2 (Wilcoxon signed-rank Test, $\mathrm{V}=81$, $\mathrm{p}$-values in figure) and the isochronous 118 1:1 categories $(\mathrm{V}=0)$ but not for the $2: 1$ category $(\mathrm{V}=313)$.

\section{References}

122 [1] Savage, P. E., Brown, S., Sakai, E., \& Currie, T. E. (2015). Statistical universals reveal the structures and 123 functions of human music. Proceedings of the National Academy of Sciences, 112(29), 8987-8992.

124 [2] Jacoby, N., \& McDermott, J. H. (2017). Integer ratio priors on musical rhythm revealed cross-culturally by 125 iterated reproduction. Current Biology, 27(3), 359-370.

126 [3] Ravignani, A., Delgado, T., \& Kirby, S. (2016). Musical evolution in the lab exhibits rhythmic 127 universals. Nature Human Behaviour, 1(1), 1-7.

128 [4] Kotz, S. A., Ravignani, A., \& Fitch, W. T. (2018). The evolution of rhythm processing. Trends in Cognitive 129 Sciences, 22(10), 896-910.

130 [5] Roeske, T. C., Tchernichovski, O., Poeppel, D., \& Jacoby, N. (2020). Categorical rhythms are shared 131 between songbirds and humans. Current Biology, 30(18), 3544-3555.

132 [6] Ravignani, A. (in press). Isochrony, vocal learning and the acquisition of rhythm and melody. Behavioral 133 and Brain Sciences. 1-87. doi:10.1017/S0140525X20000333.

134 [7] De Gregorio, C., Carugati, F., Estienne, V., Valente, D., Raimondi, T., Torti, V., Miaretsoa, L., 135 Ratsimbazafy, J., Gamba, M., Giacoma, C. (2021). Born to sing! Song development in a singing primate. 136 Current Zoology, zoab018.

137 [8] Gamba, M., et al. (2016). The indris have got rhythm! Timing and pitch variation of a primate song examined between sexes and age classes. Frontiers in Neuroscience, 10, 249.

[9] Haimoff, EH. (1986). Convergence in the Duetting of Monogamous Old World Primates. Journal of Human Evolution 15, 51-59.

[10] Savage, P. E., Loui, P., Tarr, B., Schachner, A., Glowacki, L., Mithen, S., \& Fitch, W. T. (in press). Music 

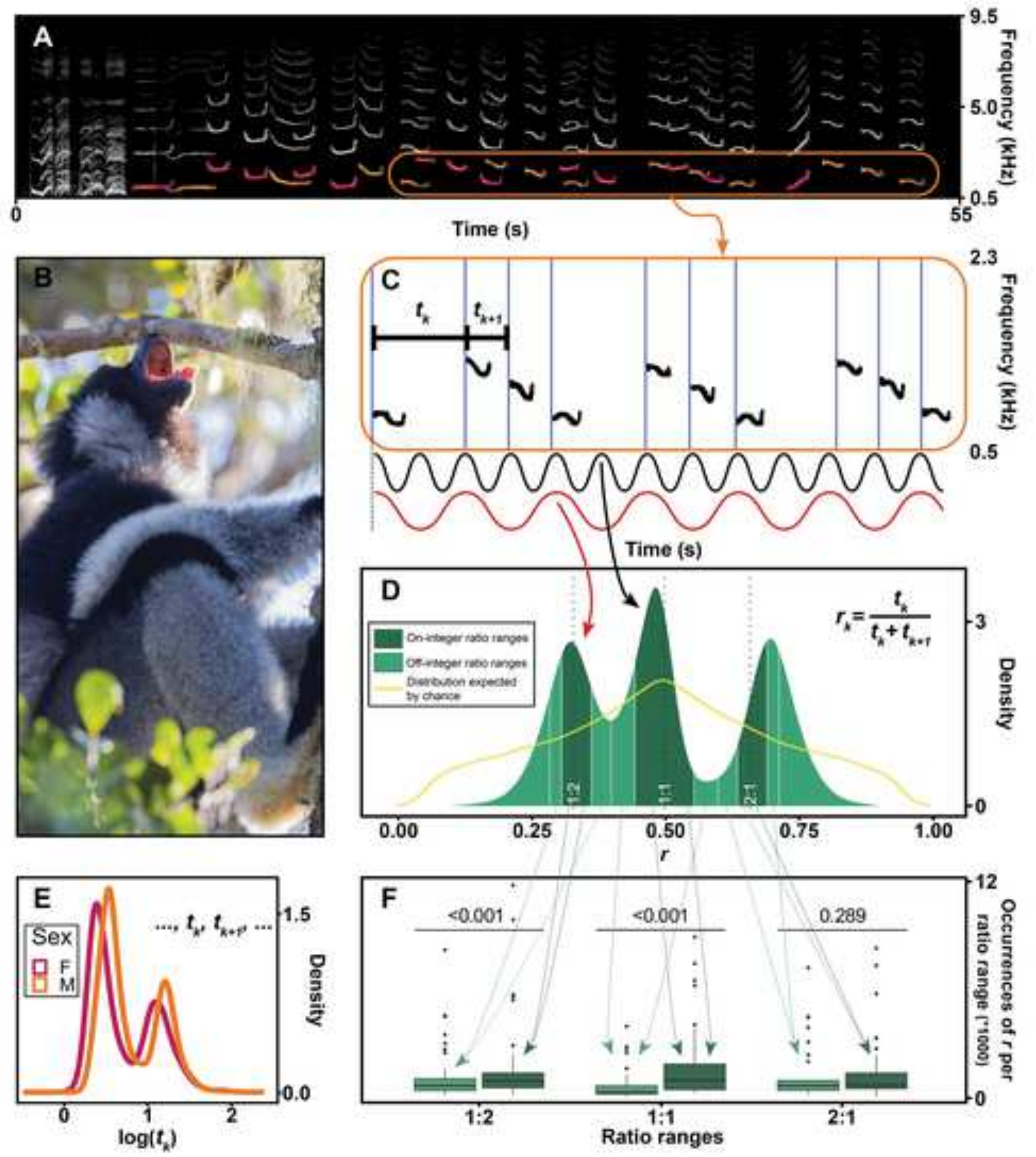


\section{Supplement - Categorical rhythms in a singing primate}

Chiara De Gregorio ${ }^{1}$, Daria Valente ${ }^{1,2}$, Teresa Raimondi ${ }^{1}$, Valeria Torti ${ }^{1}$, Longondraza Miaretsoa ${ }^{1,3}$, Olivier Friard $^{1}$, Cristina Giacoma ${ }^{1 \#}$, Andrea Ravignani ${ }^{4 \# *}$, Marco Gamba $^{1 \#}$

${ }^{1}$ Department of Life Sciences and Systems Biology, University of Turin, Turin, Italy

${ }^{2}$ Equipe de Neuro-Ethologie Sensorielle (ENES), Centre de Recherche en Neurosciences de Lyon (CRNL), CNRS, INSERM, University of Lyon/Saint-Étienne, Saint-Étienne, France

${ }^{3}$ Groupe d'Etude et de Recherche sur les Primates de Madagascar (GERP), Antananarivo, Madagascar.

${ }^{4}$ Comparative Bioacoustics Group, Max Planck Institute for Psycholinguistics, Nijmegen, The Netherlands

${ }^{\#}$ Co-senior authors.

* Correspondence: Andrea Ravignani, Comparative Bioacoustics Group, Max Planck Institute for Psycholinguistics, Wundtlaan 1,6525XD Nijmegen, The Netherlands; andrea.ravignani@mpi.nl

\section{Methods}

\section{Observations and recordings}

Indris (Indri indri) are lemurs whose ancestor diverged from ours approximately 77.5 $\mathrm{MYA}^{\mathrm{S} 1}$. Indris are classified as 'critically endangered' by the IUCN Red List of Threatened Species ${ }^{\mathrm{S} 2}$. While their population size is currently unknown, it has been estimated that only around $1000-10000$ individuals remain in the wild ${ }^{\mathrm{S} 3}$. Indris have never been successfully bred in captivity ${ }^{\mathrm{S}}$.

We recorded songs produced by 20 indri groups living in four different rainforest patches in Madagascar (Figure S1A): six groups in the Analamazaotra Reserve (Andasibe-Mantadia National Park, $18^{\circ} 56^{\prime}$ $\mathrm{S}, 48^{\circ} 25^{\prime} \mathrm{E}$ ), two groups in Mantadia (Andasibe-Mantadia National Park), three groups in the Mitsinjo Station Forestière $\left(18^{\circ} 566^{\prime} \mathrm{S}, 48^{\circ} 4^{\prime} \mathrm{E}\right)$, and nine groups in the Maromizaha Forest $\left(18^{\circ} 56^{\prime} 49^{\prime \prime} \mathrm{S}, 48^{\circ} 27^{\prime} 53^{\prime \prime} \mathrm{E}\right)$. Genetic analyses on seven groups inhabiting Maromizaha Forest confirmed that indris live in groups composed of an unrelated mating pair plus one to three individuals, usually their offspring ${ }^{\mathrm{S5}}$.

We collected data in the field from 2005 to 2016 for a total of 41 months. We observed one group per day from 06:00 a.m. to 1:00 p.m., using natural marks to identify each individual. Our analyses focused on adult reproductive individuals because temporal features in the vocalizations of adult reproductive indris may differ from those found in young or non-reproductive individuals ${ }^{\mathrm{S} 6, \mathrm{S7}}$.

We recorded songs using solid-state recorders (SoundDevices 702, Olympus S100 and LS05, and Tascam DR-100, DR-40, and DR-05) equipped with Sennheiser (ME 66 and ME 67) or AKG (CK 98) shotgun microphones. We set the recorders at a sampling rate of $44.1 \mathrm{kHz}$ and an amplitude resolution of 16 bits during all the recording sessions. We recorded the animals at a distance ranging from 2 to 20 meters, with the microphone aimed at the focal singing animals. The recordist pointed the microphone towards a particular individual and attributed each vocalization to the signaler via the focal animal sampling technique ${ }^{\mathrm{s}}$. Songs can take the form of duets when two indris (usually the reproductive pair) sing together, or choruses, when one or more non-reproductive individuals join the pair in singing. In the indris' songs, notes can be either organized in phrases or produced as isolated units. Phrases are characterized by adjacent units with a descending frequency pattern, while isolated units are single notes between two phrases. 

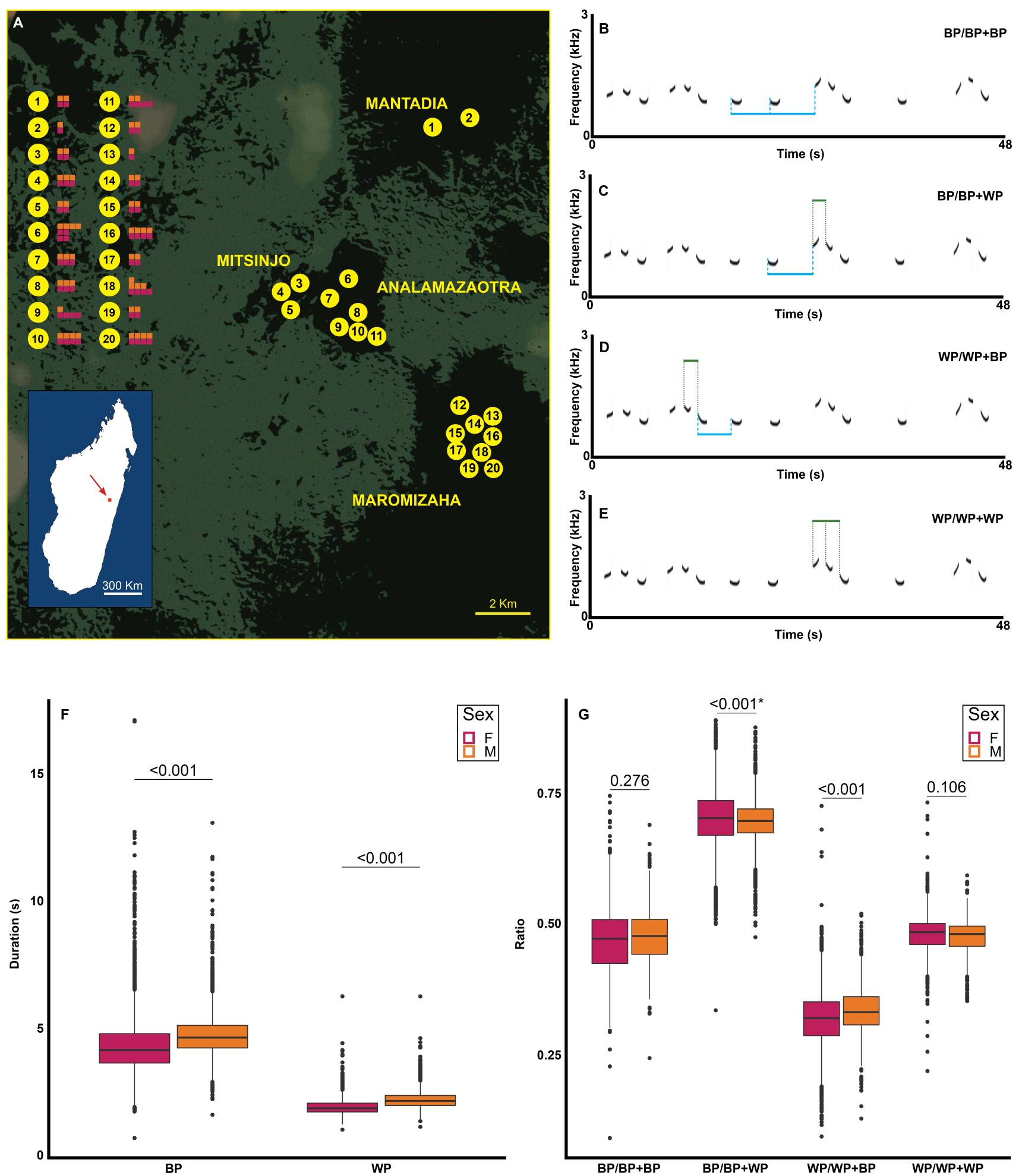

Figure S1. Song recording locations, with schematic representation of durations and ratios types and their values. (A) Map showing the four sites where indris were recorded. Yellow numbered circles represent the ID of the familiar group sampled. Colored lines next to the circles indicate that a reproductive male (orange) or female (pink) belonged to that group; the number of squares in each line denotes the number of years that individual was recorded. (B) Schematic representation of a "BP/BP+BP" $r_{k}$ type; the light blue line indicates two BP intervals: a $t_{k}$ between two isolated notes, and $a t_{k}$ between an isolated note and the first note of a phrase. (C) Schematic representation of a "BP/BP+WP" $r_{k}$ type; the light blue line indicates a BP interval, and the green line indicates a WP interval: a $\mathrm{t}_{\mathrm{k}}$ between an isolated note and the first note of a phrase, and $a t_{k}$ between the first two notes of the same phrase. (D) Schematic representation of a "WP/WP+BP" $r_{k}$ type; the light blue line indicates the BP interval, the green line indicates the WP interval: a $t_{k}$ between two notes of the same phrase, and a $t_{k}$ between a note belonging to a phrase and an isolated note. (E) Schematic representation of a "WP/WP+WP" $r_{k}$ type; the green line indicates two WP intervals: in this case a $t_{k}$ between the first and second note of the same phrase, and a $t_{k}$ between the second and third note of the same phrase. (F) Boxplots of $t_{k}$ duration by type. Notice that the WP boxplots here correspond to the first and second peaks in Figure 1E, and the BP boxplots here correspond to the third and fourth peaks in Figure 1E. (G) Boxplots of $r_{k}$ values by type. The * denotes that, although the Tukey test is statistically significant, the difference is negligible because of the small effect size of the comparison. 


\section{Acoustic analyses}

We recorded a total of 636 individual contributions uttered by 39 reproductive indris, 20 females and 19 males. Using Praat 5.3.46 ${ }^{\mathrm{S} 9}$, we edited and saved the recorded portion containing the indris' song as a single mono audio file (WAV format). Using field notes and video recordings, we then identified, annotated, and saved the onsets and offsets of each note for each individual as a Praat textgrid. We identified units and silences via visual inspection of the spectrograms. We labeled the notes, differentiating if they were organized in a sequence or produced as isolated units. Our analysis does not include 'roars', which are harsh and chaotic emissions that usually introduce the song ${ }^{\text {sio }}$.

We then labeled the silent portions of the individual contributions, differentiating silences depending if they occurred between two notes of the same phrase ("intra"), or, conversely, if they occurred between two different phrases or two different isolated notes ("inter"). For each of the above units and intervals, we extracted the timing of the starting point and duration using Praat and saved them to a Microsoft $\subset$ Excel spreadsheet $^{\mathrm{S} 11}$. We imported them in $\mathrm{R}$ ( $\mathrm{R}$ Core Team 2017; version 3.4.3) and calculated the inter-onset intervals $\left(t_{k}\right.$, Figure $\left.1 C\right)$ to evaluate the rhythmic structure of contributions ${ }^{S 12}$. Notice that a sequence of $n$ notes will produce $n-1$ inter-onset intervals, i.e. $\mathrm{t}_{1}, \ldots, \mathrm{t}_{\mathrm{n}-1}$. Based on previous work ${ }^{\mathrm{S3}, \mathrm{S7}}$, we used the information on notes and silences type (belonging to a phrase or an isolated note) to calculate two types of $t_{k}$ : the within-phrase $\mathrm{t}_{\mathrm{k}}$ (WP: Within-Phrase inter-onset intervals, that is, all and only the intervals between notes within a phrase) and the between-phrase $t_{k}$ (BP: Between-Phrase inter-onset intervals, that is, all and only the intervals between two different phrases or between two isolated notes).

We then calculated rhythmic ratios $r_{k}$ following $\operatorname{Ref}^{S 14}$, namely by dividing each $t_{k}$ for its duration plus the duration of the following interval: $r_{k}=t_{k} / t_{k}+t_{k+1}$. Since each $t_{k}$ can either be a WP or a BP, we obtained four ratio types: $\mathrm{WP} / \mathrm{WP}+\mathrm{WP}, \mathrm{WP} / \mathrm{WP}+\mathrm{BP}, \mathrm{BP} / \mathrm{WP}+\mathrm{BP}$ and $\mathrm{BP} / \mathrm{BP}+\mathrm{BP}$, depending on the type of two adjacent $\mathrm{t}_{\mathrm{k}}$. These four ratio types and their corresponding intervals in indris' songs are depicted in Figure S1B-E. Further analyses were performed both on the $t_{k}$ values and their ratios $r_{k}$.

\section{Statistical analysis}

Four main analyses were performed. All statistical analyses in 3.1-3.3 below were performed in R (R Core Team 2017; version 3.4.3). Analyses in 3.1 aimed at statistically substantiating the intuition in Figure 1E, namely that the distributions of $t_{k}$ durations have 4 distinct peaks, potentially different by sex and $t_{k}$ type. Analyses in 3.2 aimed at testing this same hypothesis on the $r_{k}$ data. Analyses in 3.3 correspond to, and provide details for, the main result reported in the manuscript and in Figure 1F. When compared to 3.3, analyses in 3.2 afford the possibility of zooming in on the overall pattern of ratios and analyzing them by sex and ratio type. In addition, comparison between results in 3.1 and 3.2 allow inference on potential sexual differences in durations and/or ratios. Finally, the simulation described in 3.4 aimed at providing a plausible baseline scenario of how empirical ratios would look if indris had no rhythmic categories.

\section{1. $t_{\mathrm{k}}$ durations}

We tested whether sex and the type of $t_{k}$ statistically predicted the inter-onset interval duration, using a Linear Mixed Model (LMM, lmer function of 1 me 4 package ${ }^{\mathrm{s} 15}$ ). Before fitting the models, $\mathrm{t}_{\mathrm{k}}$ duration was $\log$ transformed $\left(\log _{\mathrm{e}}\right)$ because it was not normally distributed. We entered the values of $t_{k}$ as response variable, and sex of the emitter, $\mathrm{t}_{\mathrm{k}}$ type (WP and BP) and their interaction as fixed factors. We included the individual's identity and the specific song contribution from which we extracted the $t_{k}$ as nested random factors. We used the Tukey test ${ }^{\mathrm{S} 16}$ to perform all the pairwise comparisons for all the interaction levels between sex and $t_{k}$ type (multiple contrast package multcomp in R).

\section{2. $\mathrm{t}_{\mathrm{k}} \operatorname{ratios}\left(\mathbf{r}_{\mathrm{k}}\right)$}

To test whether the values of $t_{k}$ ratios $\left(r_{k}\right)$ were statistically influenced by the sex of the singer and the $r_{k}$ type 
(WP/WP+WP, WP/WP+BP, BP/WP+BP and BP/BP+BP), we used a Generalised Linear Mixed Model (GLMM, glmmTMB package ${ }^{\text {S17 }}$ ) fitting a beta distribution, continuous between 0 and 1 . Beta was chosen via the package fitdistrplus ${ }^{\mathrm{S} 18}$ as suitable theoretical distribution. The values of $\mathrm{r}_{\mathrm{k}}$ were entered in the model as response variable, and sex of the emitter, $r_{k}$ type and their interaction as fixed factors. We included the individual identity and the specific song contribution from which we extracted the ratios $r_{k}$ as nested random factors. We used the Tukey test (within the multiple contrast package multcomp in R) to perform all pairwise comparisons for all levels of the interaction between sex and $r_{k}$ type and for all levels of $r_{k}$ type ${ }^{S 16}$.

For both models, we verified the assumptions of normality and homogeneity of residuals by visually inspecting the qqplot and the residuals' distribution (a function provided by R. Mundry). We also excluded the presence of collinearity among predictors based on variance inflation factors (vif package ${ }^{\mathrm{S} 19}$ ). To test for significance of our full models ${ }^{\mathrm{S} 20}$ we compared them against null models containing only the random factors, with a likelihood ratio test (Anova with argument test "Chisq", ${ }^{21}$ ). We report estimates, standard error (S.E.), zand p-values for the Tukey tests (Table S1C-E).

Finally, we used Cohen's $d$ test to compute the magnitude of the effect size for the Tukey tests' comparisons between different types of durations and ratios between the two sexes.

\subsection{Rhythmic categories: Ratios distribution and their peaks}

To evaluate the empirical occurrence of small integer ratios, following $\operatorname{Re}^{\mathrm{S} 14}$, we divided the ratio distribution into on-integer and off-integer ratio ranges, centering the on-integer ratio ranges around 1:2 (or 0.333; a fundamentally small integer ratio), 1:1 (or 0.500; corresponding to isochrony), and 2:1 (or 0.666; a fundamentally small integer ratio). While the 1:1 ratio corresponds to two intervals of equal duration, the 1:2 and 2:1 ratios correspond to the second interval being, respectively, double and half the duration of the first.

Conversely, off-integer ratio ranges were centered around $0.285,0.400,0.600$, and 0.710 ; the boundaries of all on- and off integer ratio ranges were $0.307,0.363,0.444,0.555,0.637$, and 0.693 . All these ratios were calculated according to $\mathrm{Ref}^{\mathrm{S} 14}$. We then counted all occurrences of ratio values that fell in each onand off-integer ratio range for each individual, and we normalized these counts according to the size of their range on the $\mathrm{x}_{\text {-axis }}{ }^{\mathrm{S} 14}$. Notice, for instance, how the on-integer ratio range of 1:2 in Figure 1D is narrower than the 1:1 range; normalization allowed to correct and account for this and other inequalities. The Shapiro-Wilk tests confirmed that our count data did not follow a normal distribution, so we compared on-integer and offinteger ratio ranges using three (paired) Wilcoxon signed-rank tests.

\subsection{Simulated ratio distribution}

For reference, we simulated the null ratio distribution expected by chance. The yellow line in Figure 1D is based on 100,000 simulated ratios produced using a custom script in Python 2.7.10. Based on the upper (681 $\mathrm{msec})$ and lower $(17089 \mathrm{msec})$ bound of inter-onset intervals naturally produced by indri ${ }^{\mathrm{S} 13}$, we simulated what would happen if no rhythmic categories existed by sampling inter-onset intervals from uniform distributions and calculating each ratio as in the formula in Figure 1D. In other words, this sampling simulated the distribution of the ratio between one random variable and its sum with another random variable, both random variables being uniform.

\section{$\underline{\text { Results }}$}

\section{1. $t_{\mathrm{k}}$ durations}

The average duration of $t_{k}$ was $2.114 \pm 0.298$ for WP and $4.651 \pm 1.008$ for BP. This difference emerged also in Figure $1 \mathrm{E}$, where the probability density function clearly indicated the presence of two clusters in the $t_{k}$ 
duration. Males showed longer $\mathrm{t}_{\mathrm{k}}$ than females (Figure S1F, Table S1A), both overall $(\mathrm{M}=3.429 \pm 1.372, \mathrm{~F}=$ $2.919 \pm 1.403 ; \mathrm{p}<0.001)$ and by $\mathrm{t}_{\mathrm{k}}$ type (WP: $\mathrm{M}=2.339 \pm 0.340, \mathrm{~F}=1.899 \pm 0.258 ; \mathrm{p}<0.001 ; \mathrm{BP}: \mathrm{M}=5.002$ $\pm 0.928, \mathrm{~F}=4.318 \pm 1.083 ; \mathrm{p}<0.001$; Table S1D; Figure $\mathrm{S} 1 \mathrm{~F})$. WPs had a shorter duration than BPs $(\mathrm{p}<$ 0.001; Table S1A). For the comparison between the two sexes, Cohen's d was 1.477 for WP and 0.679 for BP, confirming that the significant sexual differences were non-negligible. In brief, there is both a sexual dimorphism in durations and a significant difference between the $t_{k}$ types BP and WP, exemplified as the four peaks in Figure 1E.

\section{2. $\mathbf{t}_{\mathrm{k}}$ ratios $\left(\mathbf{r}_{\mathrm{k}}\right)$}

The average of ratios $r_{k}$ was $0.499 \pm 0.161$. Our model showed significant differences among $r_{k}$ types (Table S1B), and the Tukey test confirmed that all four $r_{k}$ types differed significantly $(\mathrm{p}<0.001$, for every comparison; Table S1C). The average $\mathrm{WP} / \mathrm{WP}+\mathrm{BP}$ was $0.324 \pm 0.054$, WP/WP+WP was $0.477 \pm 0.033, \mathrm{BP} / \mathrm{BP}+\mathrm{WP}$ was $0.698 \pm 0.054$, and $\mathrm{BP} / \mathrm{BP}+\mathrm{BP}$ was $0.470 \pm 0.068$. Notice how both values linked to isochrony $(\mathrm{BP} / \mathrm{BP}+\mathrm{BP}$ and $\mathrm{WP} / \mathrm{WP}+\mathrm{WP}$ ) are slightly smaller than 0.5 , suggesting increasing duration of adjacent intervals, i.e. ritardando.

Males presented overall higher ratio values than females $(\mathrm{p}=0.021$; Table S1B). However, the Tukey test indicated no significant sex differences for the ratios types linked to isochrony $(B P / B P+B P, p=0.276$; $\mathrm{WP} / \mathrm{WP}+\mathrm{WP}, \mathrm{p}=0.106$; Table S1E) emerged. Instead, we did find sexual dimorphism in $\mathrm{r}_{\mathrm{k}}$ type WP/WP+BP, where males showed lower values than females $(\mathrm{p}<0.001)$, and in $\mathrm{BP} / \mathrm{BP}+\mathrm{WP}$, where males were the ones showing higher values $(\mathrm{p}<0.001)$. When comparing between sexes, Cohen's $\mathrm{d}$ was 0.152 for WP/WP+WP, 0.059 for $\mathrm{BP} / \mathrm{BP}+\mathrm{BP}, 0.278$ for $\mathrm{WP} / \mathrm{WP}+\mathrm{BP}$. Instead, it was 0.111 for $\mathrm{BP} / \mathrm{BP}+\mathrm{WP}$, suggesting that this difference between males and females is negligible, even if it is statistically significant (Figure S1G). Therefore, the only actual (significant and non-negligible) difference in $r_{k}$ types concerns the value of WP/WP+BP between males and females. Notice that this value is always greater than 0.5 because BP>WP. $\mathrm{WP} / \mathrm{WP}+\mathrm{BP}$ corresponds to the third peak in Figure 1D and the third pair of boxplots in Figure 1F, also corresponding to the one non-significant peak out of three. No significant peak in Figure 1D shows sexual dimorphism. In brief, there is little sexual dimorphism in ratios and categories and no dimorphism at all for significant rhythmic categories, speaking against sexual selection hypotheses for rhythm.

Summary and details of both models and Tukey tests can be found in table S1.

\section{Rhythmic categories: Ratios distribution and their peaks}

The evaluation of the occurrence of different $r_{k}$ types indicated the presence of three clusters (green density function in Figure 1D). The comparison of this density function to the distribution expected by chance (yellow line in Figure 1D) suggested the presence of different rhythmic categories. The dependent 2-group Wilcoxon tests between on-integer and off-integer ratio ranges (Figure 1F) confirmed that indris produce songs characterized by at least two rhythmic categories: isochrony, corresponding to $1: 1$ ratio $(\mathrm{p}<0.001, \mathrm{~V}=0)$ and a $1: 2$ ratio $(\mathrm{p}<0.001, \mathrm{~V}=81)$. A $\mathrm{V}$ value of 0 for the isochronous $1: 1$ categories means that each of the 39 indris produced more on-integer than off-integer ratios, not only statistically but also numerically. However, we did not find significant differences between on-integer and off integer ratio ranges for $2: 1(p=0.289, \mathrm{~V}=313)$. In other words, the first and second (but not the third) peaks in Figure 1D result from indris producing ratios falling on small on-integer ratios rather than equally-sized off-integer neighborhoods. 


\begin{tabular}{|c|c|c|c|c|c|}
\hline [LMM] Response $\Delta$ & & Fixed Factor & Random Factors & \multicolumn{2}{|c|}{ Package } \\
\hline$t_{k}$ duration & & Sex $* t_{\mathrm{k}}$ type & ID Individual, ID contribution & \multicolumn{2}{|c|}{$\operatorname{lme} 4$} \\
\hline Predictors & Estimate & $S E$ & $d f$ & $t$ & $p$ \\
\hline (Intercept) & 1.423 & 0.028 & a & a & a \\
\hline $\mathrm{WP}^{\mathrm{b}}$ & -0.080 & 0.038 & 13770 & -207.956 & $<0.001$ \\
\hline$M^{b, c}$ & 0.163 & 0.033 & 40.130 & 5.443 & $<0.001$ \\
\hline $\mathrm{WP} * \mathrm{M}^{\mathrm{b}, \mathrm{c}}$ & 0.037 & 0.006 & 13760 & 5.875 & $<0.001$ \\
\hline [GLMM] Response $\Delta$ & & Fixed Factor & Random Factors & \multicolumn{2}{|c|}{ Package } \\
\hline $\mathbf{r}_{\mathrm{k}}$ & & Sex $* r_{k}$ type & ID Individual, ID contribution & \multicolumn{2}{|c|}{ glmmTMB } \\
\hline Predictors & Estimate & $S E$ & $z$ & \multicolumn{2}{|c|}{$p$} \\
\hline (Intercept) & -0.130 & 0.008 & a & \multicolumn{2}{|c|}{ a } \\
\hline $\mathrm{BP} / \mathrm{BP}+\mathrm{WP}^{\mathrm{b}}$ & 0.982 & 0.009 & 105.460 & \multicolumn{2}{|c|}{$<0.001$} \\
\hline $\mathrm{WP} / \mathrm{BP}+\mathrm{WP}^{\mathrm{b}}$ & -0.632 & 0.009 & -68.020 & \multicolumn{2}{|c|}{$<0.001$} \\
\hline $\mathrm{WP} / \mathrm{WP}+\mathrm{WP}^{\mathrm{b}}$ & 0.046 & 0.009 & 4.860 & \multicolumn{2}{|c|}{$<0.001$} \\
\hline $\mathrm{M}^{\mathrm{b}, \mathrm{c}}$ & 0.034 & 0.015 & 2.300 & \multicolumn{2}{|c|}{0.021} \\
\hline $\mathrm{BP} / \mathrm{BP}+\mathrm{WP} * \mathrm{M}^{\mathrm{b}, \mathrm{c}}$ & -0.069 & 0.016 & -4.170 & \multicolumn{2}{|c|}{$<0.001$} \\
\hline $\mathrm{WP} / \mathrm{BP}+\mathrm{WP} * \mathrm{M}^{\mathrm{b}, \mathrm{c}}$ & 0.040 & 0.016 & 2.430 & \multicolumn{2}{|c|}{0.015} \\
\hline $\mathrm{WP} / \mathrm{WP}+\mathrm{WP} * \mathrm{M}^{\mathrm{b}, \mathrm{c}}$ & -0.054 & 0.016 & -3.270 & \multicolumn{2}{|c|}{0.001} \\
\hline \multirow[t]{2}{*}{$\mathbf{C}$} & \multicolumn{3}{|c|}{ [Tukey Test] $\mathbf{r}_{k}$ type } & \multicolumn{2}{|c|}{ Package: multcomp } \\
\hline & Estimate & $S E$ & $z$ & \multicolumn{2}{|c|}{$p$} \\
\hline $\mathrm{BP} / \mathrm{BP}+\mathrm{WP}-\mathrm{BP} / \mathrm{BP}+\mathrm{BP}$ & 0.982 & 0.009 & 105.457 & \multicolumn{2}{|c|}{$<0.001$} \\
\hline $\mathrm{WP} / \mathrm{WP}+\mathrm{BP}-\mathrm{BP} / \mathrm{BP}+\mathrm{BP}$ & -0.632 & 0.009 & -68.021 & \multicolumn{2}{|c|}{$<0.001$} \\
\hline $\mathrm{WP} / \mathrm{WP}+\mathrm{WP}-\mathrm{BP} / \mathrm{BP}+\mathrm{BP}$ & 0.045 & 0.009 & 4.858 & \multicolumn{2}{|c|}{$<0.001$} \\
\hline $\mathrm{WP} / \mathrm{WP}+\mathrm{BP}-\mathrm{BP} / \mathrm{BP}+\mathrm{WP}$ & -1.614 & 0.006 & -259.709 & \multicolumn{2}{|c|}{$<0.001$} \\
\hline $\mathrm{WP} / \mathrm{WP}+\mathrm{WP}-\mathrm{BP} / \mathrm{BP}+\mathrm{WP}$ & -0.936 & 0.006 & -144.786 & \multicolumn{2}{|c|}{$<0.001$} \\
\hline WP/WP+WP - WP/WP+BP & 0.677 & 0.006 & 105.373 & \multicolumn{2}{|c|}{$<0.001$} \\
\hline \multirow[t]{2}{*}{$\mathbf{D}$} & \multicolumn{3}{|c|}{ [Tukey Test] $t_{k}$ type $*$ Sex } & \multicolumn{2}{|c|}{ Package: multcomp } \\
\hline & Estimate & $S E$ & $z$ & & \\
\hline (F:F) WP-BP & -0.796 & -0.796 & -207.956 & & \\
\hline (M:F) BP-BP & 0.163 & 0.038 & 5.443 & & \\
\hline (M:F) WP-BP & -0.596 & 0.030 & -19.994 & & \\
\hline (M:F) BP-WP & 0.958 & 0.030 & 32.090 & & \\
\hline (M:F) WP-WP & 0.199 & 0.030 & 6.697 & & \\
\hline (M:M) WP-BP & -0.759 & 0.005 & -153.539 & & \\
\hline $\mathbf{E}$ & & [Tukey Test] $\mathbf{r}_{1}$ & pe *Sex & Pack & ultcomp \\
\hline & Estimate & $S E$ & $z$ & & \\
\hline$(\mathrm{M}: \mathrm{F}) \mathrm{BP} / \mathrm{BP}+\mathrm{BP}-\mathrm{BP} / \mathrm{BP}+\mathrm{BP}$ & -0.796 & -0.796 & -207.956 & & \\
\hline (M:F) BP/BP+WP-BP/BP+WP & 0.163 & 0.038 & 5.443 & & \\
\hline (M:F) WP/WP+BP-WP/WP+BP & -0.596 & 0.030 & -19.994 & & \\
\hline (M:F) WP/WP+WP-WP/WP+WP & 0.958 & 0.030 & 32.090 & & \\
\hline
\end{tabular}

Table S1. Summary and details of models and Tukey tests. (A) Influence of the fixed factors on $t_{k}$ duration. Full model vs. Null model: $\chi 2=24468.48, \mathrm{df}=3, \mathrm{p}<0.001$. (B) Influence of the fixed factors on $r_{k}$ type. Full model vs. Null model: $\chi 2=30155, \mathrm{df}=11, \mathrm{p}<0.001$. (C) Results of the Tukey test for $r_{k}$ type. (D) Results of the Tukey test for the interaction between $t_{k}$ type and sex. (E) Results of the Tukey test for the interaction between $r_{k}$ type and sex.

${ }^{a}$ Not shown as not having a meaningful interpretation.

${ }^{b}$ Estimate \pm SE refer to the difference of the response between the reported level of this categorical predictor and the reference category of the same predictor.

c This predictor was dummy coded, with "SexF," being the reference category.

Statistically significant values are indicated in bold; M, males; F, females. 


\section{Acknowledgements}

This research was supported by the University of Torino and the Parco Natura Viva - Centro Tutela Specie Minacciate, with the financial assistance of the European Union, through the Project BIRD (ACP SandT Program, Contract FED/2009/217077). The authors are grateful to the local field guides and field assistants who helped out during the data collection. We would also like to thank the GERP (Groupe d'Étude et des Recherche sur les Primates de Madagascar) for their support during the field activities, and to Dr. Cesare Avesani Zaborra and Dr. Caterina Spiezio for the financial and technical support. We have received permits for this research, each year, from "Direction des Eaux et Forêts" and "Madagascar National Parks" (formerly ANGAP): 2005 [Nº197/MINENV.EF/SG/DGEF/DPB/SCBLF/RECH], 2006 [N¹72/06/MINENV.EF/SG/

DGEF/DPB/SCBLF $], \quad 2007 \quad\left[\mathrm{~N}^{\circ} 0220 / 07 / \mathrm{MINENV} . \mathrm{EF} / \mathrm{SG} / \mathrm{DGEF} / \mathrm{DPSAP} / \mathrm{SSE}\right], \quad 2008 \quad\left[\mathrm{~N}^{\circ} 258 / 08 / \mathrm{MEFT} /\right.$ SG/DGEF/DSAP/SSE], $2009 \quad\left[\mathrm{~N}^{\circ} 243 / 09 / \mathrm{MEF} / \mathrm{SG} / \mathrm{DGF} / \mathrm{DCB} . \mathrm{SAP} / \mathrm{SLRSE}\right], \quad 2010 \quad\left[\mathrm{~N}^{\circ} 118 / 10 / \mathrm{MEF} / \mathrm{SG} /\right.$ DGF/DCB.SAP/SCBSE and $\left.\mathrm{N}^{\circ} 293 / 10 / \mathrm{MEF} / \mathrm{SG} / \mathrm{DGF} / \mathrm{DCB} . \mathrm{SAP} / \mathrm{SCB}\right], \quad 2011 \quad\left[\mathrm{~N}^{\circ} 274 / 11 / \mathrm{MEF} / \mathrm{SG} / \mathrm{DGF} /\right.$ DCB.SAP/SCB $], \quad 2012 \quad\left[\mathrm{~N}^{\circ} 245 / 12 / \mathrm{MEF} / \mathrm{SG} / \mathrm{DGF} / \mathrm{DCB} . \mathrm{SAP} / \mathrm{SCB}\right], \quad 2014 \quad\left[\mathrm{~N}^{\circ} 066 / 14 / \mathrm{MEF} / \mathrm{SG} / \mathrm{DGF} /\right.$ DCB.SAP/SCB], $2015 \quad$ [N¹80/15/MEEMF/SG/DGF/DAPT/SCBT], $2016 \quad$ [Nº8/16/MEEMF/SG/DGF/ DAPT/SCB.Re and N²17/16/MEEMF/SG/DGF/DSAP/SCB.Re]. Data collection did not require a permit for 2013 because it has been performed by Malagasy citizens only.

\section{Author Contributions}

Conceptualization, C.D.G., D.V., T.R., A.R. and M.G.; Methodology, C.D.G., D.V., T.R., A.R., O.F. and M.G.; Investigation, C.D.G., D.V., V.T., T.R., and L.M..; Writing - Original Draft, A.R. and C.D.G.; Writing -Review \& Editing, M.G., V.T., T.R., D.V., and L.M..; Visualization, C.D.G, D.V., T.R., A.R. and M.G.; Supervision, M.G. and C.G.

\section{Data and Code Availability}

An example video is available as supplementary information. Data, code, and custom-written scripts are available from the corresponding author upon request.

\section{Declaration of Interests}

The authors declare no competing interests.

\section{Supplemental References}

S1. Masters, J.C., Silvestro, D., Génin, F., DelPero, M. (2013). Seeing the wood through the trees: the current state of higher systematics in the Strepsirhini. Folia Primatol. 84, 201-19.

S2. King, T., Dolch, R., Randriahaingo, H.N.T., Randrianarimanana, L. and Ravaloharimanitra, M. (2020). Indri indri. The IUCN Red List of Threatened Species 2020: e.T10826A115565566. https://dx.doi.org/10.2305/IUCN.UK.20202.RLTS.T10826A115565566.en

S3. Andriaholinirina, N., Baden, A., Blanco, M., Chikhi, L., Cooke, A., Davies, N., Dolch, R., Donati, G., Ganzhorn, J., Golden, C., Groeneveld, L.F., Hapke, A., Irwin, M., Johnson, S., Kappeler, P., King, T., Lewis, R., Louis, E.E., Markolf, M., Mass, V., Mittermeier, R.A., Nichols, R., Patel, E., Rabarivola, C.J., Raharivololona, B., Rajaobelina, S., Rakotoarisoa, G., Rakotomanga, B., Rakotonanahary, J., Rakotondrainibe, H., Rakotondratsimba, G., Rakotondratsimba, M., Rakotonirina, L., Ralainasolo, F.B., Ralison, J., Ramahaleo, T., Ranaivoarisoa, J.F., Randrianahaleo, S.I., Randrianambinina, B., Randrianarimanana, L., Randrianasolo, H., Randriatahina, G., Rasamimananana, H., Rasolofoharivelo, T., Rasoloharijaona, S., Ratelolahy, F., Ratsimbazafy, J., Ratsimbazafy, N., Razafindraibe, H., Razafindramanana, J., Rowe, N., Salmona, J., Seiler, M., Volampeno, S., Wright, P., Youssouf, J., Zaonarivelo, J., Zaramody, A. (2020). Indri indri. The IUCN Red List of Threatened Species. Version $2020-3$. https://www.iucnredlist.org

S4. Britt, A., Randriamandratonirina, N.J., Glasscock, K.D., Iambana, B.R. (2002). Diet and feeding behaviour of Indri indri in a low-altitude rain forest. Folia Primatol. 73, 225-239.

S5. Torti, V., Bonadonna, G., De Gregorio, C., Valente, D., Randrianarison, R.M., Friard, O., Pozzi, L., Gamba, M., Giacoma, C. (2017). An intra-population analysis of the indris' song dissimilarity in the light of genetic distance. Sci. Rep. 7, 10140 . 
S6. Gamba, M., Torti, V., Estienne, V., Randrianarison, R.M., Valente, D., Rovara, P., Bonadonna, G., Friard, O., Giacoma, C. (2016). The indris have got rhythm! Timing and pitch variation a primate song examined between sexes and age classes. Front. Neurosci. 10, 249.

S7. De Gregorio, C., Carugati, F., Estienne, V., Valente, D., Raimondi, T., Torti, V., Miaretsoa, L., Ratsimbazafy, J., Gamba, M., Giacoma, C. (2021). Born to sing! Song development in a singing primate. Curr. Zool., zoab018.

S8. Altmann, J. (1974). Observational study of behavior: sampling methods. Behaviour 49, 227-267.

S9. Boersma, P., and Weenink, D. (2008). Praat: Doing Phonetics by Computer (Computer Program). Available online at: http://www.praat.org

S10. Pollock, J. I. (1986). The song of the indris (Indri indri; Primates: Lemuroidea): natural history, form, and function. Int. J. Primatol. 7, 225-264.

S11. Gamba, M., and Giacoma, C. (2007). Quantitative acoustic analysis of the vocal repertoire of the crowned lemur. Ethol. Ecol. Evol. 19, 323-343.

S12. Sasahara, K., Tchernichovski, O., Takahasi, M., Suzuki K, Okanoya K. (2015). A rhythm landscape approach to the developmental dynamics of birdsong. J. R. Soc. Interface 12, 20150802.

S13. De Gregorio, C., Zanoli, A., Valente, D., Torti, V., Bonadonna, G., Randrianarison, R.M., Giacoma, C., Gamba, M. (2019). Female indris determine the rhythmic structure of the song and sustain a higher cost when the chorus size increases. Curr. Zool. 65, 89-97.

S14. Roeske, T. C., Tchernichovski, O., Poeppel, D., Jacoby, N. (2020). Categorical rhythms are shared between songbirds and humans. Curr. Biol. 30, 3544-3555.

S15. Bates, D., Mächler, M., Bolker, B., Walker, S. (2015). Fitting linear mixed-effects models using lme4. J. Stat. Softw. $67,1-48$.

S16. Bretz, F., Hothorn, T., Westfall, P. (2010). Multiple Comparisons Using R. Boca Raton (FL): Chapman \& Hall/CRC Press.

S17. Brooks, M.E., Kristensen, K., van Benthem, K.J., Magnusson, A., Berg, C.W., Nielsen, A., Skaug, H.J., Maechler, M., Bolker, B.M. (2017). glmmTMB Balances Speed and Flexibility Among Packages for Zero-inflated Generalized Linear Mixed Modeling. R. J. 9, 378-400.

S18. Delignette-Muller, and M.L., Dutang, C. (2015). fitdistrplus: An R Package for Fitting Distributions. J. Stat. Softw. $64,1-34$.

S19. Fox, J., and Weisberg, S. (2011). An R companion to applied regression. 2nd edn.Thousand Oaks (CA): SAGE Publications, Inc.

S20. Forstmeier, W., and Schielzeth, H. (2011). Cryptic multiple hypotheses testing in linear models: overestimated effect sizes and the winner's curse. Behav. Ecol. Sociobiol. 65, 47-55.

S21. Dobson, A. J. (2002). An Introduction to Generalized Linear Models, 2nd Edn. Boca Raton, FL: Chapman and Hall/CRC Press. 